\title{
Impact of cover crop on soil carbon accrual in topographically diverse terrain
}

\author{
J. Beehler, J. Fry, W. Negassa, and A. Kravchenko
}

\begin{abstract}
Farmers must consider real-world problems and variability to maximize yields and minimize environmental impacts when using cover crops in corn (Zea mays L.)-based cropping systems. Much of the variability encountered by farmers of the Midwest Corn Belt is due to the topographical diversity of the undulating landscape. The objectives of this study are to explore the effects of cover crops on soil organic carbon (C), both total organic $\mathrm{C}$ and its labile form, particulate organic C (POC), and on water retention at contrasting topographies (summit, slope, and depression). A cereal rye (Secale cereal L.) cover crop was established in the fall of 2011 at two experimental sites. At each site, the experimental design was a split-split plot with whole plot factor, topographical position, in a randomized complete block design with two replications. Topographical position affected all studied plant and soil characteristics, including aboveground plant biomass, rye residue decomposition, POC, total soil C, and soil water retention. Across all topographical positions, rye residue decomposition was $\sim 5 \%$ greater in the treatment with than without cover crop. In slopes and summits, the POC in the treatment with cover crop was significantly $\left(\sim 0.7 \mathrm{mg} \mathrm{g}^{-1}\right.$ soil $\left.[\sim 700 \mathrm{ppm}]\right)$ greater than in the treatment without the cover crop; however, the difference was not statistically significant in depressions. The cover crop effect on both total organic C and soil water retention levels was not statistically significant. The study points to potential interactions between topography and $\mathrm{C}$ sequestration benefits of cover crops; however, longer experimental times are needed to detect significant differences in soil total $\mathrm{C}$ and water retention measurements.
\end{abstract}

Key words: cover crops—-soil carbon—sustainable corn—-topography

Cover crops can provide multiple benefits to row crop agricultural systems, including suppression of weeds and pests, improvement of soil and water quality, and stimulation of nutrient cycles (Snapp et al. 2005). Yet, when implementing cover cropping farmers must consider spatial variability within their fields to maximize yields and minimize environmental impacts. In the Midwest Corn Belt, much of the spatial variability that farmers encounter is due to the topographical diversity of the undulating landscape. The topographical diversity controls many soil properties, including the distribution of soil organic carbon (SOC).

Enhancing rotation through the inclusion of a cover crop has the potential to accumulate SOC (West and Post 2002; Follett 2001). Cereal rye (Secale cereale L.) is especially suited for this purpose because it is a high biomass grass known to increase SOC (Kuo and Jellum 2000; Kaspar et al. 2006;
Spatial distribution patterns of soil moisture and temperature are among the factors that likely contribute to SOC accrual. They influence the environment for crop growth and regulate the conditions for microbial growth and activity (Wickings et al. 2016), thus can affect the decomposition of freshly added plant inputs. Topographical differences are often the main controls of soil moisture and soil temperature in undulating terrain.

Topography plays a role in the spatial variability of soil physical properties, which are highly correlated to SOC content (Moore et al. 1992; Tromp-van Meerveld and McDonnell 2006; Romano and Palladino 2002). One such property of significant value to plant growth and strongly related to SOC is soil water retention (Hudson 1994; Adams 1973; Rawls 1983; Gupta and Larson 1979). An increase in organic matter in sandy soils, like the soils in this study, can lead to an increase of water retention (Rawls et al. 2003). Organic matter content in the soil also affects soil aggregation, a key component of soil structure and water retention capability (Franzluebbers 2002). By assessing the effects of topography and cover cropping on water retention we can better understand the long-term implications on soil $\mathrm{C}$ and soil health. However, relatively few studies so far have directly addressed the effect of cover crops on soil hydraulic properties, including soil water retention.

The principal hypothesis of this study is that topography does not only influence the spatial distribution patterns of SOC and water retention, but also moderates the cover cropping benefits, specifically the cover crop's contributions to SOC accrual. We hypothesize that topography's role is implemented, first, through its influence on the growth of the main crops and cover crops and on the subsequent biomass inputs into the soil, and second, through its influence on plant (Muñoz et al. 2014). Thus, one can expect that greater SOC benefits from a rye cover crop can occur in topographical depressions. The recent observations from topographically diverse agricultural fields in Michigan demonstrated that the magnitude of the cover crop effects on SOC was higher in the summit and slope positions as compared to depressions (Ladoni et al. 2016). This indicates that other factors, besides the overall amount of the aboveground cover crop biomass production, influence the magnitude of the SOC benefits in topographically diverse agricultural landscapes.
Jordan Beehler is a graduate research assistant al Sciences at Michigan State University, East Lansing, Michigan. Jessica Fry is a graduate research assistant in the Department of Plant, Soil, and Microbial Sciences at Michigan State University, East Lansing, Michigan. Wakene Negassa is a research fellow with the Global Soil Forum at the Institute for Advanced Sustainability Studies, Potsdam, Germany. Alexandra Kravchenko is a professor in the Department of Plant, Soil, and Microbial Sciences at Michigan State University, East Lansing, Michigan. in the Department of Plant, Soil, and Microbi- 
residue decomposition rates. We address the former by measuring aboveground biomass of the main crops and cover crops, and the latter by assessing decomposition of cover crop residue using the litterbag approach.

The objectives of this study are to explore the effect of a rye cover crop on soil C accrual and changes in soil water retention characteristics in topographically diverse agricultural landscapes. Total SOC responds relatively slowly to management practices (Plaza-Bonilla et al. 2014; Haynes 2000). However, labile SOC, such as particulate organic matter, can respond to changes in land use and management practices on the scale of a few days to a few years (Nascente et al. 2013). Thus, while reporting the observed total SOC results in this study, we used particulate organic $\mathrm{C}$ (POC) as a metric of the changes in SOC driven by the addition of a cover crop to the system.

\section{Materials and Methods}

Site Description. The two experimental sites of this study are located in central (Mason) and southwest (Kellogg) Michigan. Both sites average around $76 \mathrm{~cm}$ (29.9 in) of rainfall in addition to $76 \mathrm{~cm}$ of snowfall annually. Temperatures at both sites average $-3^{\circ} \mathrm{C}$ $\left(26.6^{\circ} \mathrm{F}\right)$ in winter and $20^{\circ} \mathrm{C}\left(68^{\circ} \mathrm{F}\right)$ in summer.At Mason, the soil is Marlette fine sandy loam (Oxyaquic Glossudalfs), 2\% to $6 \%$ slope, consisting of mainly sandy loam with sandy clay loam present at the $20 \mathrm{~cm}(7.8$ in) depth. At Kellogg, the soil is Kalamazoo loams (Typic Hapludalfs) with $2 \%$ to $6 \%$ slope and mainly sandy loam with fine to medium gravels.

At each of the sites, the experimental design was a split-split plot with the whole plot factor of topographical position in a randomized complete block design with two replications. The treatment design included the following three factors: topography with three levels (summit, slope, and depression), main crop with two levels (corn [Zea mays L.] and soybean [Glycine max L.]), and cover crop with two levels (presence and absence). Note that including both phases of the rotation (corn and soybean) in the experiment doubled the number of experimental plots, thus, at each topographical position each cover crop treatment had four experimental plots for a total of 12 plots of each cover crop treatment at each experimental site. The cover crop experimental plots were $9.1 \times 9.1$ $\mathrm{m}(29.8 \times 29.8 \mathrm{ft})$ in size.
Conventional practices were used in tillage, planting, the application of fertilizer and herbicide, and harvesting consistent with practices in the region. The cereal rye cover crop was established each fall in early October, beginning in 2011. During 2011 to 2013, rye was sown at $112 \mathrm{~kg} \mathrm{ha}^{-1}\left(99.9 \mathrm{lb} \mathrm{ac}^{-1}\right)$ with a John Deere $4.57 \mathrm{~m}$ (15 ft) no-till drill. In 2014 to 2015 , rye population was increased to establish a better stand and was sown at 145 $\mathrm{kg} \mathrm{ha}^{-1}\left(129.3 \mathrm{lb} \mathrm{ac}^{-1}\right)$. Rye was terminated by herbicide and then was chisel plowed, followed by a soil finisher to establish a seed bed for the subsequent main crop. Weeds were controlled using herbicides at least once per growing season with additional weed control by herbicide application if necessary.

Soil samples for total SOC and water retention were taken in the spring of 2015 Samples for SOC were taken from 0 to $10 \mathrm{~cm}$, 10 to $20 \mathrm{~cm}, 20$ to $40 \mathrm{~cm}$, and 40 to $60 \mathrm{~cm}$ ( 0 to 4 in, 4 to 7.8 in, 7.8 to 15.7 in, and 15.7 to 23.6 in) depths. Samples for water retention were taken from 0 to $10 \mathrm{~cm}$ and 10 to $20 \mathrm{~cm}$ depths. For SOC analyses, three cores were taken per each plot and composited; for water retention analyses, three soil cores per each plot were taken and processed separately. Particulate organic matter samples were collected separately once a year in the springs from 2012 to 2014 at 0 to $10 \mathrm{~cm}$ depth.

Plant Biomass Sampling and Carbon Analysis. Biomass of corn and soybean at each plot was collected at harvest each year. Whole plants of corn and soybean were collected, then the grain was separated from the vegetative biomass and both were weighed to obtain measurements for yield and vegetative biomass.

Rye biomass was collected immediately before termination every year. Three random samples per plot were collected by using a $0.3 \times 0.3 \mathrm{~m}(1 \times 1 \mathrm{ft})$ sampling square. All the rye in the sampling square was cut at the soil surface to obtain the aboveground biomass. The rye was weighed, dried at $65^{\circ} \mathrm{C}$ $\left(149^{\circ} \mathrm{F}\right)$, and then weighed again to obtain a dry biomass measurement.

Carbon content of plant biomass was measured by combustion analysis using a Costech ECS 4010 CHNSO Analyzer (Costech Analytical Technologies, Inc., Valencia, California). We choose to present the total $\mathrm{C}$ content in the aboveground biomass of the main and cover crops instead of biomass values as the metric most consistent with the SOC-processes focus of this study.
Rye Decomposition. Rye was collected from each field site prior to termination to use in the decomposition assessment by litterbag approach. Litterbags were $20 \times 20$ $\mathrm{cm}(7.8 \times 7.8 \mathrm{in})$ and were constructed with $0.028 \mathrm{~cm}$ (0.01 in) plastic mesh. The rye was oven dried at $40^{\circ} \mathrm{C}\left(104^{\circ} \mathrm{F}\right)$, and a random subsample of 5 to $7 \mathrm{~g}$ ( 0.17 to $0.24 \mathrm{oz})$ of hand-cut dried rye, measuring approximately 5 to $7 \mathrm{~cm}$ (2 to 2.7 in) in length, was placed in each bag. In 2015, 60 litterbags were buried at $10 \mathrm{~cm}$ (4 in) depth in the plots with cover crop at the Mason site. In 2016, 340 litterbags were buried at $10 \mathrm{~cm}$ depth in the plots with and without cover crop at both Mason and Kellogg sites. Litterbags were removed at three time points of approximately one, three, and five weeks after the initial placement, which was at the beginning of the main crop growing season in the spring. After the litterbags were removed, the decomposed rye was cleaned of soil and other debris, oven dried at $65^{\circ} \mathrm{C}\left(149^{\circ} \mathrm{F}\right)$ and weighed (Alef 1995).

Total Soil Organic Carbon. Soil samples were collected using a Giddings hydraulic probe (Giddings Machine Company, Windsor, Colorado) $(7.6 \mathrm{~cm} \mathrm{[3} \mathrm{in]} \mathrm{in} \mathrm{diam-}$ eter). Approximately $0.7 \mathrm{~kg}(1.5 \mathrm{lb})$ of field moist soil from each depth increment was sieved to pass a $2 \mathrm{~mm}$ (0.07 in) sieve and air-dried. A $5 \mathrm{~g}(0.17 \mathrm{oz})$ subsample was then ground to a fine powder using an 8500 Shatterbox (Spex Sample Prep, Metuchen, New Jersey) in preparation for flash combustion analysis by the Carlo Erba EA 1108 (CE Elantec Inc., Lakewood, New Jersey). Values were corrected for small amounts of inorganic $\mathrm{C}$ at the Mason site through the acetic acid neutralization method.

Particulate Organic Carbon. Approximately $20 \mathrm{~g}(0.7 \mathrm{oz})$ of soil was subsampled from the sieved and air-dried soil to use for POC analysis. Particulate organic C was chemically dispersed using a 5\% sodium hexametaphosphate $\left(\left[\mathrm{NaPO}_{3}\right]_{6}\right)$ solution. The soil solution was then passed through a 53-micron sieve. The contents of the sieve were oven dried at $60^{\circ} \mathrm{C}\left(140^{\circ} \mathrm{F}\right)$ and ground in the 8500 Shatterbox (Cambardella and Elliott 1992). Final C analysis of the samples were conducted using a Costech ECS 4010 CHNSO Analyzer.

Water Retention. Soil samples for water retention analysis were collected in the spring before corn or soybean planting in brass rings $5.5 \mathrm{~cm}$ (2.1 in) in diameter and $3 \mathrm{~cm}$ (1.2 in) in height. Pressure plates were 
used to extract water at pressures of 0.05 bar, 0.1 bar, 0.33 bar, 1 bar, and 3 bar. The water content at 15 bar was measured by drying subsamples of the soil used from the pressure plate method and placing them in a desiccator above an oversaturated potassium chloride $(\mathrm{KCl})$ solution $\left(500 \mathrm{~g} \mathrm{KCl} \mathrm{L}^{-1}\right.$ [66.76 oz KCl gal-1] water) for two months. For both methods, the difference in mass was used to calculate water content.

Statistical Analysis. Statistical analysis was performed using the MIXED procedure of SAS 9.4 (SAS Institute Inc., Cary, North Carolina). The statistical model for the analysis included presence/absence of cover crop, topographical position, and the interaction between them as fixed factors. Blocks nested within topography at each site were included in the model as the random effect and were used as an error term for testing the main effect of topography. When the interaction between topography and cover crops was statistically significant $(p<0.1)$, we used slicing to assess the effect of the cover crop presence at each topography level and the effect of topography at each level of the cover crop factor. When slicing effects were statistically significant $(p<0.1)$, comparisons between the means were conducted using $t$-tests. Because of high variability of the collected field data, we reported the results that were statistically significant at both 0.05 and 0.1 levels of significance.

\section{Results and Discussion}

We present the results in the order consistent with the hypothesized influences of cover crops and topography on the soil C processes that were considered in this study. Specifically, we start with topographical and cover crop effects on the main crop biomass, followed by topographical effect on the rye biomass, then topographical and cover crop effects on litter decomposition, and finally on POC, total soil organic C, and soil water retention.

Plant Biomass Carbon. The highest aboveground biomass of main crops, corn and soybean, and hence the highest amount of $\mathrm{C}$ in the aboveground biomass, were observed in depressions, followed by summits, and were the lowest in the slopes (figure 1a). Since the differences in the $\mathrm{C}$ contents of main crops in the presence or absence of the cover crop were not statistically significant, the results from both cover crop treatments were combined. An opposite trend was observed in the aboveground biomass of the rye cover crop, which tended to be the lowest in depressions of both experimental sites (figure 1b); however, the differences were not statistically significant.

Positive effects of lower topography on the main crop yield observed in this study are consistent with published results where the yield of both corn and soybean were reported to be higher in depressions and/or concave sites (Kravchenko and Bullock 2000; Jiang and Thelen 2004; Da Silva and Alexandre 2005; Timlin et al. 1998). However, poor rye growth in depression positions of this study is contradictory to the results reported by Ladoni et al. (2016) from nearby large-scale agricultural fields. The discrepancy can be explained by greater extremity of depression positions used in this study, which represented poorly drained and often flooded areas. Depression positions used by Ladoni et al (2016) were of a less extreme nature and typically had tile drainage. Negassa et al. (2015) in a study conducted at the same sites with a focus on rye growth and greenhouse gas emissions observed rye growth and impact consistent with our results.

Opposite trends in topographical effects on main and cover crops can be explained by their different growing seasons. Rye's growth primarily occurs during the cold and wet weather of falls and springs, when wet and cold depressions delay growth, in contrast to drier and warmer summits and slopes. The main crops, corn and soybean, grow during the summer when, if the weather is dry, it is advantageous to be in wetter depressions.

Rye Decomposition. Consistent with expectations, rye decomposition in depressions was higher than in slope and summit positions (figure 2). This trend was apparent in both 2015 and 2016, although the magnitude of decomposition was different between the two years. This was related to differences in weather patterns. In 2016, the presence of the cover crops tended to enhance decomposition at all topographical positions during first two sampling times (week 1 and week 2). By week 5 , the amounts of decomposed residue were similar across all topographical positions and in both treatments with and without cover crops. Negassa et al's (2015) study at the same experimental sites reported greater carbon dioxide $\left(\mathrm{CO}_{2}\right)$ emissions at depression positions than on slopes and summits. They also observed greater $\mathrm{CO}_{2}$ emissions due to cover crop presence, however only in topographical depressions.
Decomposition and $\mathrm{CO}_{2}$ emissions are controlled in large part by soil moisture, temperature, and other variables that drive microbial activity (Raich and Potter 1995; Trumbore et al. 1996; Harrison-Kirk et al. 2013). Better soil moisture and soil temperature conditions leading to an increase of microbial activity and diversity explain the higher decomposition and $\mathrm{CO}_{2}$ emissions in depressions. In nearby experimental fields, Wickings et al. (2016) observed microbial activity up to $55 \%$ higher in depression positions when compared to summits and slopes. Also, greater plant diversity is known to increase diversity and activity of soil microbial communities (Broughton and Gross 2000), which probably explains faster decomposition of rye residue in cover crop treatment's soil of this experiment.

Particulate Organic Carbon. Overall, depressions contained more POC than summits and slopes (figure 3). Presence of cover crops resulted in significantly higher POC levels, but only in the slope and summit topographical positions $(\alpha=0.1)$.

Greater amounts of POC in the depressions probably result from greater biomass inputs from the main crops there, as well as from historical deposition of plant residue transported from higher topographies. Particulate organic matter is prone to downhill redistribution through erosion, eventually becoming concentrated in depression areas (Dungait et al. 2013; Cambardella et al. 1994).

It should be noted that while historically both losses of POC from higher topographies and its gains at lower topographies were likely taking place, during this study only the losses of particulate organic matter from summit and slope positions could have occurred. No gains in POC in depressions were possible because the plots were separated by wide grass alleys ( 10 $\mathrm{m}[\sim 32.8 \mathrm{ft}])$. While erosion was not measured in this study, it is known that presence of cover crops can substantially reduce erosion (Jacinthe et al. 2004), thus it can be assumed that in summit and slope positions greater erosion was taking place in plots without cover crops than those with cover crops. Therefore, the observed increases in POC due to cover crop presence in summits and slopes can be attributed to two causes: (1) greater rye cover crop growth at summits and slopes as compared to depression positions (figure $1 \mathrm{~b}$ ) and (2) potential POC losses due to erosion from the experimental plots without cover crops. 


\section{Figure 1}

Average total carbon (C) in (a) main crop (corn and soybean) biomass and (b) rye biomass across topographical positions for each site. In (a) the letters represent statistically significant differences among topographical positions across both sites $(p<0.1)$. In (b) the effect of topography was not significant at Mason or Kellogg. Bars represent standard errors.

(a)

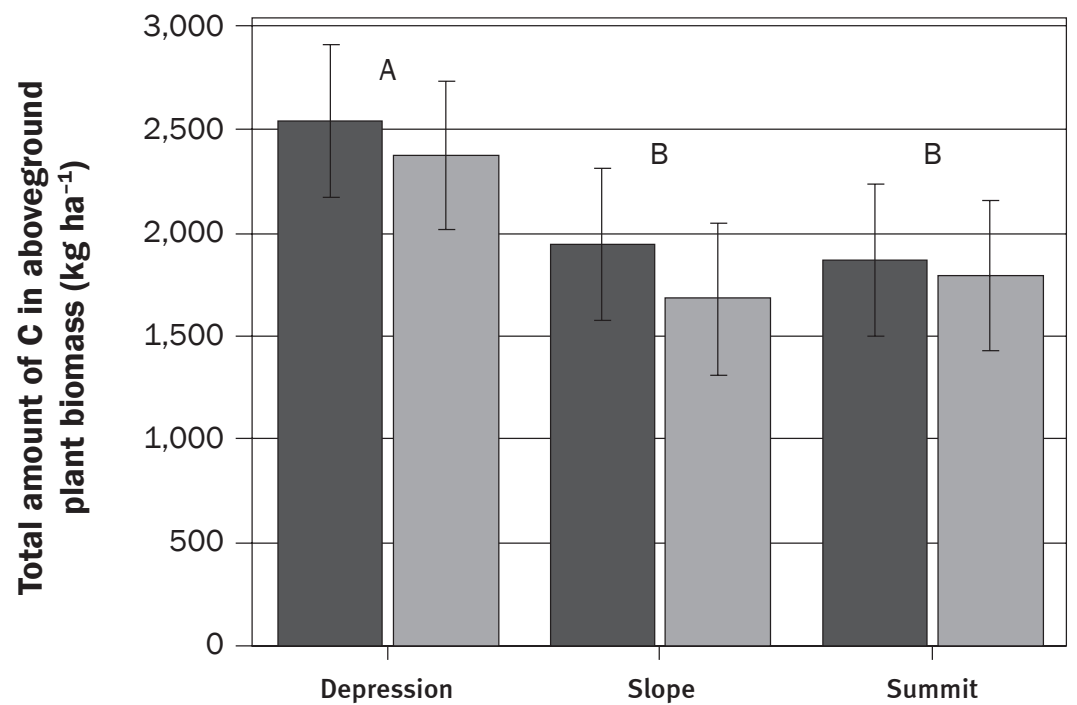

Topographical position

\section{Legend}

No cover crop $\square$ Cover crop

(b)

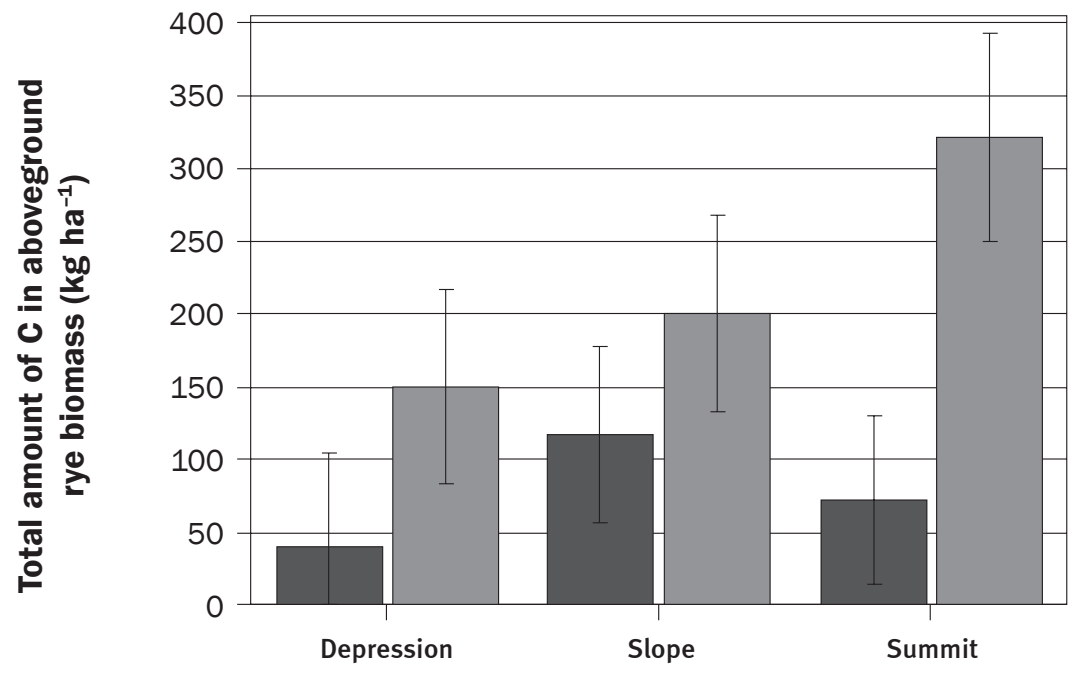

Topographical position
Note that this study does not account for the portion of $\mathrm{C}$ inputs from underground biomass, such as roots and root exudates. Belowground biomass inputs might have contributed to the greater impact of the cover crop on the summit and slope positions (Gale et al. 2000). Plants in the summits and slopes could have been devoting more energy to finding soil water and expanding their root system than the plants in depressions (Unger and Kaspar 1994).

Total Soil Organic Carbon. Total organic soil C followed the trend depression $>$ summit $>$ slope, but there were no significant differences between treatments with and without cover crops (table 1). The changes in total SOC might not become detectable until 7 to 10 years or more after changing management practices (Duiker and Lal 1999; Al-Kaisi et al. 2005). Thus, lack of statistical significance in total SOC results of this study were expected and consistent with other studies that did not observe statistically significant increases in total soil C (Kaspar et al. 2006; Basche et al. 2016).

Water Retention. Topography affected soil water retention at 0 to $10 \mathrm{~cm}(0$ to 4 in) depth and at a lesser extent at 10 to 20 $\mathrm{cm}$ (4 to 7.8 in) depth (table 2). Depression soil tended to have significantly higher water retention at saturation (table 2). More differences in topographical position were observed in both cover and no cover plots in lower pressures than in higher pressures at the 0 to $10 \mathrm{~cm}$ depth.

The differences between water retention data in the treatments with and without cover crops were not statistically significant. As with total SOC, a longer study duration appears to be necessary to observe significant changes in soil water retention due to cover crop use in the studied soil.

\section{Summary and Conclusions}

The study assessed the effects of adding rye cover crop to corn-soybean rotation in topographically diverse terrain at two experimental sites in Michigan. The aboveground biomass production by main (corn and soybean) crops was higher in topographical depressions than in summits and slopes, while the aboveground biomass of the rye cover crop followed an opposite trend. Thus, greater $\mathrm{C}$ inputs from the cover crop likely occurred in summit and slope positions. Decomposition of rye residue was greater in depressions than in summits and slopes. 
Figure 2

Rye decomposition (\%) at Kellogg and Mason experimental sites in (a,b,c) 2015 and (d,e,f) 2016. Letters indicate significant differences among topographical positions within each year and each sampling time $(p<0.1)$, stars indicate the instances in 2016 when decomposition in cover crop treatment was significantly higher than in the no cover treatment $(p<0.05)$. (a) and (d) indicate depression. (b) and (e) indicate slope. (c) and (f) indicate summit.

(a)

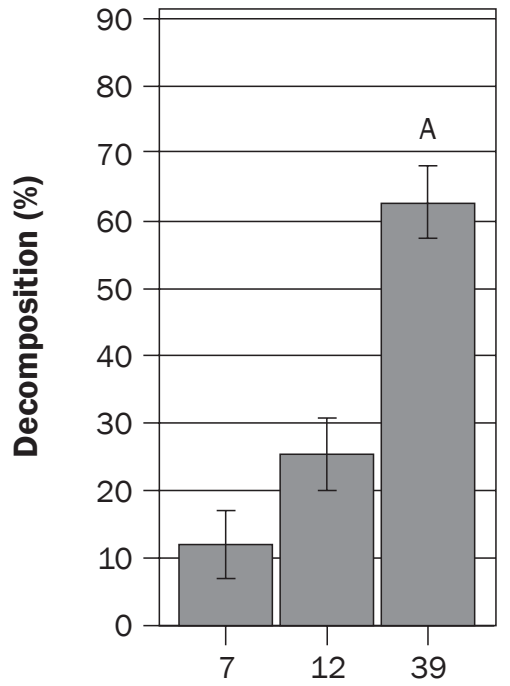

Time (days)

(d)

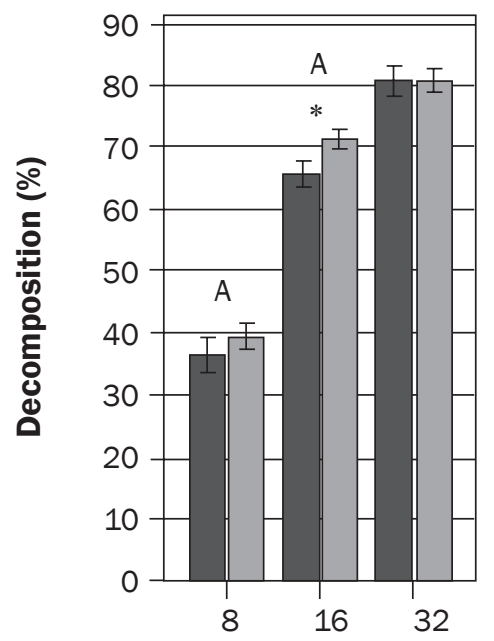

Time (days) (b)

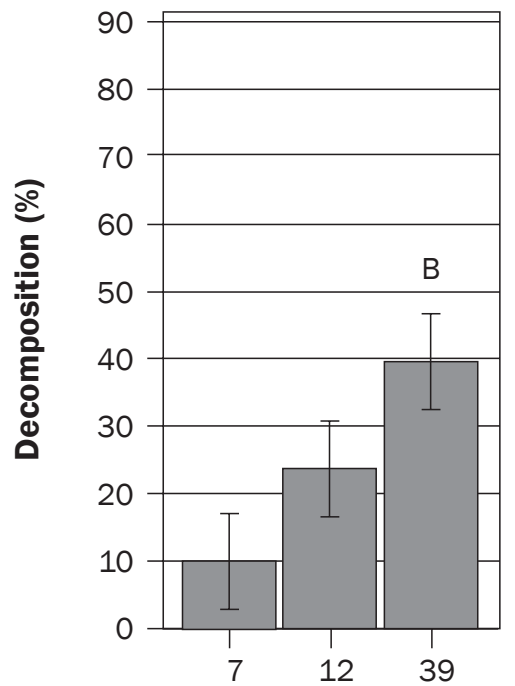

Time (days)

(e)

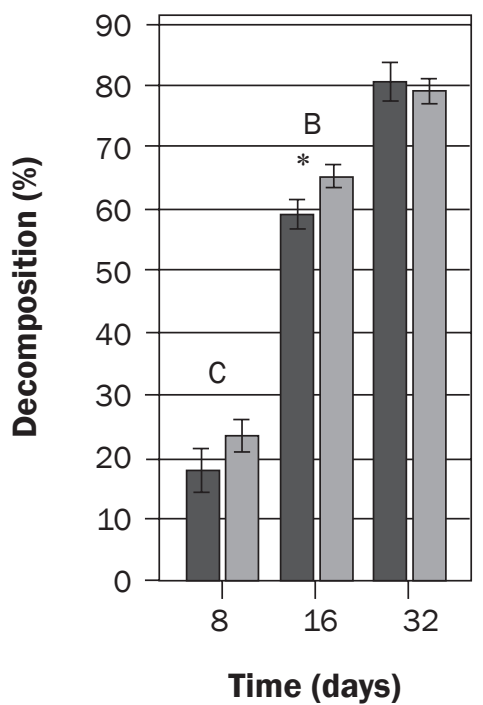

(c)

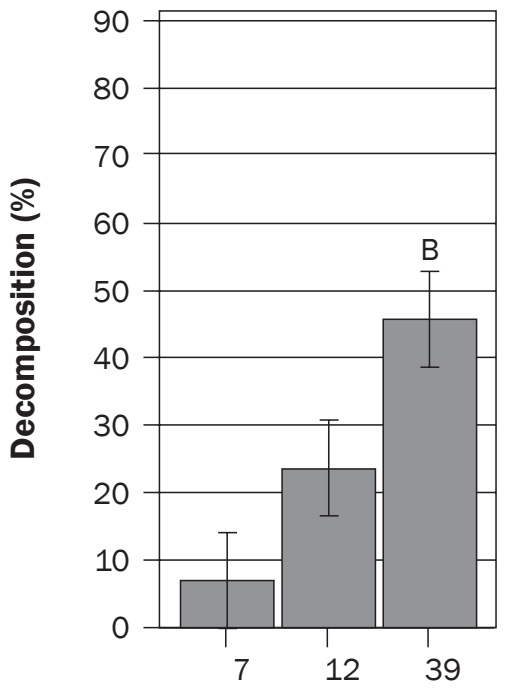

Time (days)

(f)

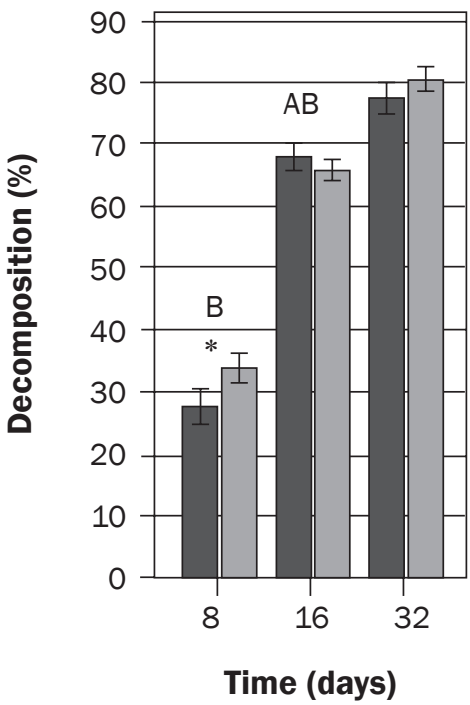

However, across all topographical positions, the presence of the cover crop in the rotation resulted in faster decomposition of the rye residue. Greater rye inputs in summit and slope positions along with potential reduction in erosion-driven soil losses from these positions led to greater POC levels in the treatment with the cover crop. No significant differences between treatments with and without cover crop were observed in depression positions. Even though the observed increases in POC due to cover crop presence point to a tendency for soil C accrual, no significant differences between treatments with and without cover crop were observed in terms of the total soil C. In terms of soil water retention, there were also no significant differences between treatments with and without cover crop. This result indicates the need for greater study duration to generate detectable effects of cover crops on these soil characteristics. 


\section{Figure 3}

Particulate organic carbon (C) at the studied topographical positions and cover crop treatments at o to $10 \mathrm{~cm}$ depth across both experimental sites. Letters within no cover treatment represent statistically significant differences among the topographical positions $(p<0.1)$. There were no significant differences among the positions in the cover crop treatment. Asterisks mark the topographical positions where the difference between treatments with and without cover crop were statistically significant $(p<0.1)$.

(a)

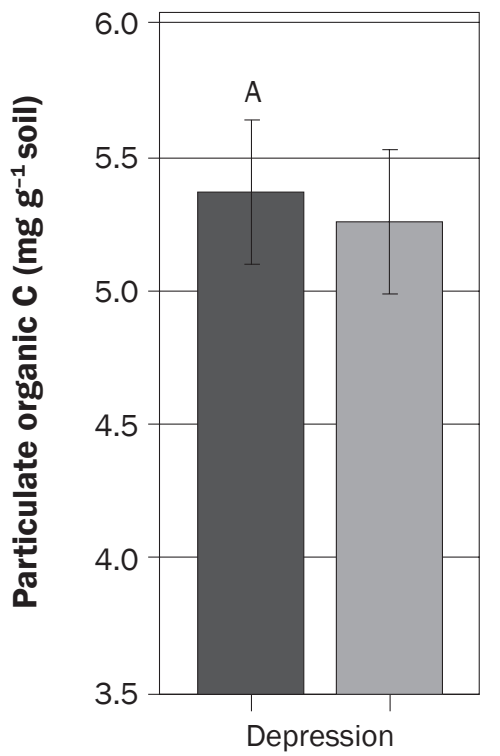

(b)

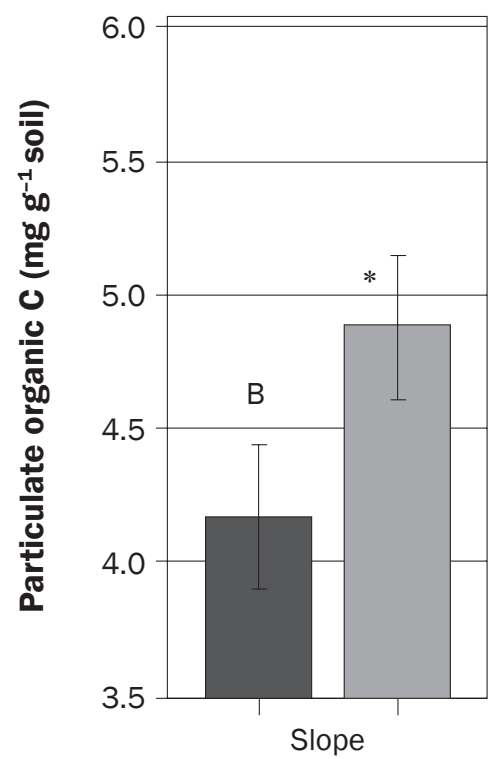

(c)

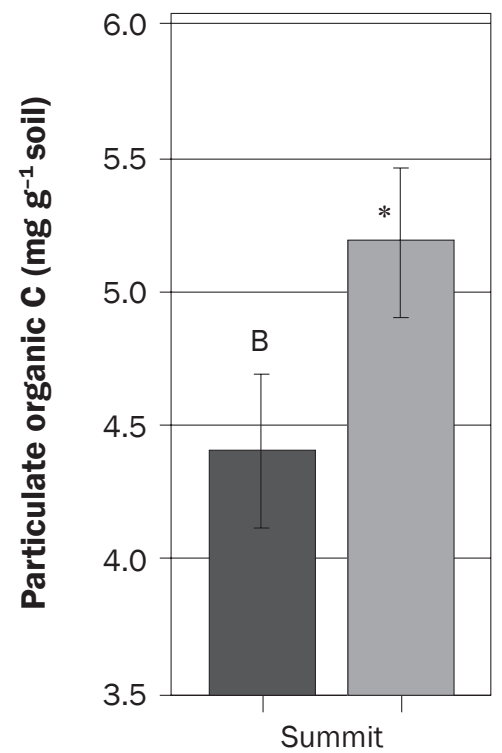

Legend

No cover crop

Cover crop

Table 1

Soil organic carbon (C) concentration (\%) at the four studied depths of the two experimental sites in spring of 2015.

\begin{tabular}{|c|c|c|c|c|c|c|c|c|c|}
\hline \multirow{3}{*}{ Site } & \multirow{3}{*}{ Topographic position } & \multicolumn{8}{|c|}{ Soil organic C concentration (\%) } \\
\hline & & \multicolumn{8}{|c|}{ Depth (cm) } \\
\hline & & \multicolumn{2}{|l|}{0 to 10} & \multicolumn{2}{|l|}{10 to 20} & \multicolumn{2}{|c|}{20 to 40} & \multicolumn{2}{|c|}{40 to 60} \\
\hline \multirow[t]{2}{*}{ Kellogg } & Depression & $0.81 \mathrm{~b} \dagger$ & $0.83 b$ & $0.71 b$ & 0.71 & 0.44 & 0.45 & 0.24 & 0.30 \\
\hline & Slope & $0.54 a$ & $0.52 a$ & $0.43 a$ & 0.51 & 0.33 & 0.39 & 0.17 & 0.25 \\
\hline \multirow{2}{*}{ Mason } & Slope & $0.79 a$ & $0.74 a$ & $0.56 a$ & $0.54 a$ & 0.42 & 0.34 & 0.39 & 0.23 \\
\hline & Summit & $0.76 a$ & $0.76 a$ & $0.59 a b$ & $0.58 a$ & 0.35 & 0.27 & 0.28 & 0.25 \\
\hline
\end{tabular}

* "Yes" corresponds to the treatment with cover crops. "No" corresponds to the treatment without cover crops.

†Within each site, each depth, and each cover treatment the letters mark the statistically significant differences among the topographical positions $(p<0.1)$. No letters are shown when the differences were not statistically significant.

\section{Acknowledgements}

This research was funded in part by the regional collaborative project supported by the USDA National Institute of Food and Agriculture (NIFA), Award No. 2011-6800230190, Cropping Systems Coordinated Agricultural Project: Climate Change, Mitigation, and Adaptation in Corn-based Cropping Systems. The authors would like to thank Rich Price, research assistant at Michigan State University in East
Lansing, Michigan, for technical assistance to the project; Kurt Spokas, soil scientist, and his lab, USDA Agricultural Research Service (ARS) in St. Paul, Minnesota, for conducting soil organic carbon (C) analyses; Lisa Tiemann, assistant professor of soil biology at Michigan State University in East Lansing, Michigan, and her lab for assisting with measuring plant material C content; as well as all the graduate and undergraduate students that assisted with data collection for this project.

\section{References}

Adams, W.A. 1973. The effect of organic matter on the bulk and true densities of some uncultivated podzolic soils. Journal of Soil Science 24(1):10-17.

Alef, K., and Nannipieri, P. 1995. Methods in Applied Soil Microbiology and Biochemistry. Amsterdam: Elsevier.

Al-Kaisi, M.M., and X. Yin. 2005. Tillage and crop residue effects on soil carbon and carbon dioxide emission in 
Table 2

Volumetric water content at all pressures at the two studied depths of the two experimental sites in the spring of 2015.

\begin{tabular}{|c|c|c|c|c|c|c|c|c|c|c|c|c|c|c|c|c|c|c|}
\hline \multirow[b]{4}{*}{ Site } & \multirow[b]{4}{*}{$\begin{array}{l}\text { Topographic } \\
\text { position }\end{array}$} & \multirow[b]{4}{*}{$\begin{array}{l}\text { Depth } \\
\text { (cm) }\end{array}$} & \multicolumn{16}{|c|}{ Volumetric water content $\left(\mathrm{cm}^{3} \mathrm{~cm}^{-3}\right)$} \\
\hline & & & \multicolumn{16}{|c|}{ Negative pressure (bar) } \\
\hline & & & \multicolumn{2}{|l|}{0} & \multicolumn{2}{|l|}{0.003} & \multicolumn{2}{|l|}{0.05} & \multicolumn{2}{|l|}{0.01} & \multicolumn{2}{|l|}{0.33} & \multicolumn{2}{|l|}{1} & \multicolumn{2}{|l|}{3} & \multicolumn{2}{|l|}{$\underline{15}$} \\
\hline & & & Yes* & No & Yes & No & Yes & No & Yes & No & Yes & No & Yes & No & Yes & No & Yes & No \\
\hline \multirow[t]{3}{*}{ Mason } & Depression & 0 to 10 & $0.46 \mathrm{~b} \dagger$ & 0.41 & 0.40 & 0.38 & $0.34 b$ & 0.29 & $0.33 b$ & 0.28 & 0.28 & 0.24 & 0.26 & 0.22 & 0.26 & 0.21 & 0.026 & 0.022 \\
\hline & Slope & 0 to 10 & $0.40 a$ & 0.40 & 0.36 & 0.35 & $0.31 a$ & 0.30 & $0.31 a b$ & 0.30 & 0.27 & 0.27 & 0.25 & 0.24 & 0.24 & 0.24 & 0.028 & 0.028 \\
\hline & Summit & 0 to 10 & $0.42 a$ & 0.39 & 0.35 & 0.36 & $0.30 \mathrm{a}$ & 0.30 & $0.29 a$ & 0.30 & 0.26 & 0.26 & 0.23 & 0.24 & 0.22 & 0.24 & 0.024 & 0.023 \\
\hline \multirow[t]{3}{*}{ Mason } & Depression & 10 to 20 & $0.44 b$ & 0.44 & 0.39 & 0.37 & 0.30 & 0.29 & 0.33 & 0.28 & 0.25 & 0.24 & 0.24 & 0.22 & 0.23 & 0.22 & 0.025 & 0.026 \\
\hline & Slope & 10 to 20 & $0.40 a$ & 0.39 & 0.34 & 0.33 & 0.30 & 0.29 & 0.29 & 0.28 & 0.27 & 0.26 & 0.25 & 0.24 & 0.24 & 0.24 & 0.027 & 0.030 \\
\hline & Summit & 10 to 20 & $0.40 a b$ & 0.42 & 0.35 & 0.35 & 0.28 & 0.30 & 0.28 & 0.29 & 0.26 & 0.27 & 0.24 & 0.25 & 0.24 & 0.25 & 0.030 & 0.026 \\
\hline \multirow[t]{3}{*}{ Kellogg } & Depression & 0 to 10 & 0.47 & 0.47 & $0.44 b$ & $0.44 b$ & $0.35 b$ & $0.36 \mathrm{~b}$ & $0.32 b$ & $0.33 b$ & 0.29 & 0.29 & $0.27 b$ & 0.27 & 0.25 & $0.27 b$ & $0.026 a$ & 0.025 \\
\hline & Slope & 0 to 10 & 0.42 & 0.43 & $0.37 a$ & $0.39 a$ & $0.25 a$ & $0.26 a$ & $0.23 a$ & $0.24 a$ & - & 0.26 & $0.17 a$ & 0.18 & 0.18 & $0.18 a$ & $0.034 b$ & 0.031 \\
\hline & Summit & 0 to 10 & 0.47 & 0.48 & $0.43 b$ & $0.45 b$ & $0.35 b$ & $0.35 b$ & $0.32 b$ & $0.32 b$ & 0.29 & 0.28 & $0.27 b$ & 0.26 & 0.25 & $0.24 a b$ & $0.023 a$ & 0.022 \\
\hline \multirow[t]{3}{*}{ Kellogg } & Depression & 10 to 20 & 0.44 & 0.44 & 0.42 & 0.41 & $0.34 b$ & 0.34 & 0.32 & 0.32 & 0.30 & 0.30 & 0.28 & 0.28 & 0.26 & 0.27 & $0.027 a$ & $0.028 a$ \\
\hline & Slope & 10 to 20 & 0.39 & 0.39 & 0.37 & 0.36 & $0.26 a$ & 0.27 & 0.25 & 0.25 & 0.19 & 0.27 & 0.20 & 0.22 & 0.19 & 0.22 & $0.037 \mathrm{~b}$ & $0.037 \mathrm{~b}$ \\
\hline & Summit & 10 to 20 & 0.47 & 0.45 & 0.43 & 0.41 & $0.32 a$ & 0.32 & 0.30 & 0.30 & 0.27 & 0.28 & 0.26 & 0.27 & 0.24 & 0.25 & $0.023 a$ & $0.025 a$ \\
\hline
\end{tabular}

* "Yes" corresponds to the treatment with cover crops. "No" corresponds to the treatment without cover crops.

†Within each site, each depth, and each cover treatment the letters mark the statistically significant differences among topographical positions $(p<0.1)$. No letters are shown when the differences were not statistically significant.

corn-soybean rotations. Journal of Environmental Quality 34(2):437-445

Basche, A.D., S.V. Archontoulis, T.C. Kaspar, D.B. Jaynes,

T.B. Parkin, and F.E. Miguez. 2016. Simulating long-

term impacts of cover crops and climate change on crop production and environmental outcomes in the Midwestern United States. Agriculture, Ecosystems and Environment 218:95-106.

Broughton, L.C., and K.L. Gross. 2000. Patterns of diversity in plant and soil microbial communities along a productivity gradient in a Michigan old-field. Oecologia 125:420-427.

Cambardella, C.A., and E.T. Elliott. 1992. Particulate soil organicmatter changes across a grassland cultivation sequence. Soil Science Society of America Journal 56(3): 777-783.

Cambardella, C.A., T.B. Moorman, T.B. Parkin, D.L. Karlen, J.M. Novak, R.F. Turco, and A.E. Konopka. 1994. Field-scale variability of soil properties in central Iowa soils. Soil Science Society of America Journal 58(5):1501-1511.

Da Silva, J.M., and C. Alexandre. 2005. Spatial variability of irrigated corn yield in relation to field topography and soil chemical characteristics. Precision Agriculture 6(5):453-466.

Duiker, S.W., and R. Lal. 1999. Crop residue and tillage effects on carbon sequestration in a Luvisol in central Ohio. Soil and Tillage Research 52(1):73-81.

Dungait, J.A., C. Ghee, J.S. Rowan, B.M. McKenzie, C. Hawes, E.R. Dixon, E. Paterson, and D.W. Hopkins. 2013. Microbial responses to the erosional redistribution of soil organic carbon in arable fields. Soil Biology and Biochemistry 60:195-201.
Follett, R.F. 2001. Soil management concepts and carbon sequestration in cropland soils. Soil and Tillage Research 61(1):77-92

Franzluebbers, A.J. 2002. Water infiltration and soil structure related to organic matter and its stratification with depth. Soil and Tillage Research 66(2):197-205.

Gale, W.J., C.A. Cambardella, and T.B. Bailey. 2000. Rootderived carbon and the formation and stabilization of aggregates. Soil Science Society of America Journal 64(1):201-207.

Gupta, S., and W.E. Larson. 1979. Estimating soil water retention characteristics from particle size distribution, organic matter percent, and bulk density. Water Resources Research 15(6):1633-1635.

Harrison-Kirk, T., M.H. Beare, E.D. Meenken, and L.M. Condron. 2013. Soil organic matter and texture affect responses to dry/wet cycles: Effects on carbon dioxide and nitrous oxide emissions. Soil Biology and Biochemistry 57:43-55.

Haynes, R.J. 2000. Labile organic matter as an indicator of organic matter quality in arable and pastoral soils in New Zealand. Soil Biology and Biochemistry 32(2): 211-219.

Hudson, B.D. 1994. Soil organic matter and available water capacity. Journal of Soil and Water Conservation 49(2):189-194.

Jacinthe, P.A., R. Lal, L.B. Owens, and D.L. Hothem. 2004. Transport of labile carbon in runoff as affected by land use and rainfall characteristics. Soil and Tillage Research 77:111-123

Jiang, P., and K.D.Thelen. 2004. Effect of soil and topographic properties on crop yield in a north-central corn-soybean cropping system. Agronomy Journal 96(1):252-258.

Kaspar, T.C., T.B. Parkin, D.B. Jaynes, C.A. Cambardella, D.W. Meek, and Y.S. Jung. 2006. Examining changes in soil organic carbon with oat and rye cover crops using terrain covariates. Soil Science Society of America Journal 70(4):1168-1177.

Kravchenko, A.N., and D.G. Bullock. 2000. Correlation of corn and soybean grain yield with topography and soil properties. Agronomy Journal 92(1):75-83.

Kuo, S., and E.J. Jellum. 2000. Long-term winter cover cropping effects on corn (Zea mays L.) production and soil nitrogen availability. Biology and Fertility of Soils 31(6):470-477.

Ladoni, M., A. Basir, P.G. Robertson, and A.N. Kravchenko. 2016. Scaling-up: Cover crops differentially influence soil carbon in agricultural fields with diverse topography. Agriculture, Ecosystems and Environment 225:93-103.

Moore, T.R., W. De Souza, and J.F. Koprivnjak. 1992. Controls on the sorption of dissolved organic carbon by soils. Soil Science 154(2):120-129.

Muñoz, J.D., J.P. Steibel, S. Snapp, and A.N. Kravchenko. 2014. Cover crop effect on corn growth and yield as influenced by topography. Agriculture, Ecosystems and Environment 189:229-239.

Nascente, A.S., Y.C. Li, and C.A.C. Crusciol. 2013. Cover crops and no-till effects on physical fractions of soil organic matter. Soil and Tillage Research 130:52-57.

Negassa, W., R.F. Price, A. Basir, S.S. Snapp, and A. Kravchenko. 2015. Cover crop and tillage systems effect on soil $\mathrm{CO}_{2}$ and $\mathrm{N}_{2} \mathrm{O}$ fluxes in contrasting topographic positions. Soil and Tillage Research 154:64-74.

Plaza-Bonilla, D., J. Álvaro-Fuentes, and C. CanteroMartínez. 2014. Identifying soil organic carbon fractions sensitive to agricultural management practices. Soil and Tillage Research 139:19-22. 
Raich, J.W., and C.S. Potter. 1995. Global patterns of carbon dioxide emissions from soils. Global Biogeochemical Cycles 9(1):23-36.

Rawls, W.J. 1983. Estimation soil bulk density from particle size analysis and organic matter content. Soil Science 135(2):123-125.

Rawls, W.J., Y.A. Pachepsky, J.C. Ritchie, T.M. Sobecki, and H. Bloodworth. 2003. Effect of soil organic carbon on soil water retention. Geoderma 116(1):61-76.

Reicosky, D.C., and F. Forcella. 1998. Cover crop and soil quality interactions in agroecosystems. Journal of Soil and Water Conservation 53(3):224-229.

Romano, N., and M. Palladino. 2002. Prediction of soil water retention using soil physical data and terrain attributes. Journal of Hydrology 265(1):56-75.

Snapp, S.S., S.M. Swinton, R. Labarta, D. Mutch, J.R. Black, R. Leep, J. Nyiraneza, and K. O'Neil. 2005. Evaluating cover crops for benefits, costs and performance within cropping system niches. Agronomy Journal 97(1):322-332.

Timlin, D.J.,Y. Pachepsky,V.A. Snyder, and R.B. Bryant. 1998. Spatial and temporal variability of corn grain yield on a hillslope. Soil Science Society of America Journal 62(3):764-773.

Tromp-van Meerveld, H.J., and J.J. McDonnell. 2006. On the interrelations between topography, soil depth, soil moisture, transpiration rates and species distribution at the hillslope scale. Advances in Water Resources 29(2):293-310.

Trumbore, S.E., O.A. Chadwick, and R. Amundson. 1996 Rapid exchange between soil carbon and atmospheric carbon dioxide driven by temperature change. Science 272(5260).

Unger, P.W., and T.C. Kaspar. 1994. Soil compaction and root growth: A review. Agronomy Journal 86(5):759-766.

West, T.O., and W.M. Post. 2002. Soil organic carbon sequestration rates by tillage and crop rotation. Soil Science Society of America Journal 66(6):1930-1946.

Wickings, K., A.S. Grandy, and A.N. Kravchenko. 2016. Going with the flow: Landscape position drives differences in microbial biomass and activity in conventional, low input, and organic agricultural systems in the Midwestern US. Agriculture, Ecosystems and Environment 218:1-10. 